\begin{tabular}{cc|c}
\hline Tar. Bil. Der. & Journal of Agricultural Sciences \\
& $\begin{array}{c}\text { Dergi web sayfası: } \\
\text { www.agri.ankara.edu.tr/dergi }\end{array}$ & Journal homepage: \\
& www.agri.ankara.edu.tr/journal
\end{tabular}

\title{
Bazı Kışlık Kolza (Brassica napus L.) Çeşitlerinin Çimlenme Döneminde Tuz Stresine Tepkilerinin Belirlenmesi
}

\author{
Mesut UYANIKa ${ }^{\text {, Şevket Metin KARA }}{ }^{\text {b }}$, Kürşat KORKMAZ \\ a Ankara Üniversitesi, Ziraat Fakültesi, Tarla Bitkileri Bölümü, Ankara, TÜRKIYE \\ ${ }^{\boldsymbol{b}}$ Ordu Üniversitesi, Ziraat Fakültesi, Tarla Bitkileri Bölümü, Ordu, TÜRKIYE \\ ${ }^{c}$ Ordu Üniversitesi, Ziraat Fakültesi, Toprak Bilimi ve Bitki Besleme Bölümü, Ordu, TÜRKIYE
}

\section{ESER BILGİisi}

Araştırma Makalesi

DOI: 10.1501/Tarimbil 0000001295

Sorumlu Yazar: Mesut UYANIK, E-posta: mesut.uyanikk@gmail.com, Tel: +90 (312) 5961284

Geliş Tarihi: 26 Kasım 2013, Düzeltmelerin Gelişi: 16 Şubat 2014, Kabul:14 Mart 2014

\section{ÖZET}

$\mathrm{Bu}$ araştırma, bazı kışlık kolza çeşitlerinin çimlenme döneminde tuz stresine tepkilerinin belirlenmesi amacıyla laboratuar koşullarında yapılmıştır. Egc 7571, Elvis, Es Hydromel ve Triangle olmak üzere 4 kışlık kolza çeşidinin yer aldığı çalışma, Tesadüf Parselleri Deneme Deseni'ne göre 3 tekerrürlü olarak yürütülmüştür. Denemede çeşitlere 8 farklı $\mathrm{NaCl}$ dozu $(0,25,50,75,100,125,150$ ve $200 \mathrm{mM})$ uygulanmış ve ele alınan çeşitlerde çimlenme oranı, çimlenme süresi, kökçük uzunluğu ve sürgün uzunluğu incelenmiştir. Elde edilen sonuçlara göre, çimlenme oran1 \% $65.33-$ 100.00, çimlenme süresi 3.75-8.71 gün, kökçük uzunluğu $0.50-12.81 \mathrm{~cm}$ ve sürgün uzunluğu $0.59-8.79 \mathrm{~cm}$ arasında değişmiş olup, $\mathrm{NaCl}$ dozları incelenen özellikler üzerine önemli oranda olumsuz etki yapmıştır. Çeşitler, çimlenme oranı bakımından tuz stresine $125 \mathrm{mM} \mathrm{NaCl}$ dozuna kadar dayanabilmiş, bu düzeyden sonra çimlenme oranında önemli düşüşler görülmüştür. Diğer özelliklerde ise çeşitler genel olarak tuz stresine $100 \mathrm{mM} \mathrm{NaCl}$ dozuna kadar tolerans gösterebilmiş, bu noktadan sonra keskin düşüşler görülmüştür. İncelenen tüm özelliklerde, Egc 7571 çeşidi artan tuz dozlarından daha az etkilenirken, Elvis en fazla etkilenen çeşit olarak dikkati çekmiştir.

Anahtar Kelimeler: Brassica napus; Kanola; Çimlenme oranı; $\mathrm{NaCl}$ dozu; Kolza

\section{Determination of Responses of Some Winter Canola (Brassica napus L.) Cultivars to Salt Stress at Germination Period}

\author{
ARTICLE INFO \\ Research Article \\ Corresponding Author: Mesut UYANIK, E-posta: mesut.uyanikk@gmail.com, Tel: +90 (312) 5961284 \\ Received: 26 November 2013, Received in Revised Form: 16 February 2014, Accepted: 14 March 2014
}

\section{ABSTRACT}

This study was carried out in laboratory conditions to determine responses of some winter-canola cultivars to salt stress at germination period. The laboratory experiment with four winter canola cultivars; i.e. Egc 7571, Elvis, Es Hydromel and Triangle, was set up as completely randomized design with 3 replications. In the experiment, eight different $\mathrm{NaCl}$ 
doses $(0,25,50,75,100,125,150$ and $200 \mathrm{mM})$ were applied to the cultivars and germination rate, germination time, radicula length and shoot length were examined. The results revealed that $\mathrm{NaCl}$ doses had a significant negative effect on all characters and germination rate, germination time, radicula length and shoot length ranged as $65.33-100.00 \%, 3.75-$ 8.71 days, $0.50-12.81 \mathrm{~cm}, 0.59-8.79 \mathrm{~cm}$, respectively. Considering germination rate, the cultivars tolerated the salt stress up to $125 \mathrm{mM} \mathrm{NaCl}$ dose, but after this level germination rate decreased significantly. In terms of the other characters, the cultivars tolerated the salt stress up to $100 \mathrm{mM} \mathrm{NaCl}$ with a significant decline after this level. Considering all attributes evaluated, Egc 7571 was less affected by $\mathrm{NaCl}$ doses while Elvis appeared to be the most salt-affected cultivar. Keywords: Brassica napus; Canola; Germination rate; $\mathrm{NaCl}$ dose; Rapeseed

(C) Ankara Üniversitesi Ziraat Fakültesi

\section{Giriş}

Bitkisel üretimde stres, bitki üzerinde olumsuz etki oluşturan dış etmen olarak tanımlanmaktadır (Türkan 2008). Bitkilerde strese neden olan faktörler ise, biyotik stres faktörleri (hastalık ve zararlılar) ve abiyotik stres faktörleri (tuzluluk, kurakl1k, düşük ve yüksek sıcaklıklar vb.) olmak üzere ikiye ayrilmaktadır.

Bir abiyotik stres faktörü olan tuzluluk; özellikle kurak ve yarı kurak iklim bölgelerinde yıkanarak yeraltı suyuna karışan çözünebilir tuzların, yüksek taban suyuyla birlikte kapillarite yoluyla toprak yüzeyine çıkması ve buharlaşma sonucu suyun topraktan ayrılarak, tuzun toprak yüzeyinde ve yüzeye yakın bölümünde birikmesi olayıdır (Ergene 1982). Tuzluluk, özellikle hassas çeşitlerde bitkisel üretimi sınırlayan en önemli sorunlardan birisi olup, ülkemizde yaklaşık 1.5 milyon hektar alanda tuzluluk ve alkalilik sorunu bulunmaktadır. $\mathrm{Bu}$ durum, sulamaya uygun arazilerimizin yaklaşık $\% 32.5$ 'inin tuzluluk stresinin etkisinde olduğunu göstermektedir. (Ekmekçi et al 2005; Zadeh \& Naeni 2007). Bitkilerde tuza tolerans bakımından familya, cins ve türler arasında önemli farklılıklar bulunmakta; hatta aynı tür içindeki çeşitler bile tuzluluktan farklı etkilenmektedir. Tuz stresi bitkilerin tüm gelişme dönemlerini etkilemesine rağmen, pek çok bitki türünde tuz stresine en hassas dönemin çimlenme dönemi olduğu bildirilmektedir (Khan et al 2000; Kuşvuran et al 2007; Zamani et al 2010). Nitekim toprak çözeltisindeki tuzlar suyun ozmotik basıncını artırarak; $\mathrm{Na}^{+}$ve $\mathrm{Cl}^{-}$iyonları ise toksik etki yaparak çimlenmeyi olumsuz etkilemektedir (Mohammadi 2009). Tuzluluğun sorun olduğu bölgelerde, toprak tuzlulaşması nispeten yavaş seyretse bile, zamanla kaçınılmaz olduğu için, genetik dayanıma yönelmek en kalıcı çözüm olarak görülmektedir. Tuzlu topraklarda ekonomik tarım için üretilmek istenen bitkinin tuza toleransının bilinmesi, üreticiye ekonomik yönden büyük yarar sağlayacaktır. Bu bağlamda, gerek ülkemizde ve gerekse dünya genelinde pek çok kültür bitkisi üzerinde tuzluluk çalışmaları yapılmış ve yapılmaya devam edilmektedir (Şekeroğlu et al 1999; Kara \& Keser 2001; Öncel \& Keleş 2002; Doğan et al 2009). Tuzluluk kolzada da bitki gelişimini olumsuz yönde etkilemekte ve verimde önemli azalmalara yol açmaktadır (Ashraf \& McNeilly 2004). Ülkemiz yağ bitkileri içerisinde önemini giderek artıran, yağ açığımızın kapatılmasında alternatif bir bitki olan ve son yıllarda gerek dünyada ve gerekse ülkemizde ekim alanı ve üretimi önemli miktarda artan kolzanın, gelişme dönemlerine göre tuza toleransının geniş bir şekilde belirlenmesi gerekmektedir. $\mathrm{Bu}$ gerekçeden hareketle bu çalışmada, farklı tuz konsantrasyonlarının ülkemizde üretimi yapılan bazı kışlık kolza çeşitlerinin çimlenmesi üzerine etkisi araştırılmıştır.

\section{Materyal ve Yöntem}

Bazı kışlık kolza (Brassica napus L.) çeşitlerinin çimlenme döneminde tuz stresine tepkilerini belirlemek amacıyla yapılan bu çalışma, Ordu Üniversitesi Ziraat Fakültesi laboratuarında 2011 yılında yapılmıştır. Tesadüf Parselleri Deneme Deseni'ne göre 3 tekerrürlü olarak kurulan denemede materyal olarak; Egc 7571, Elvis, Es Hydromel ve 
Triangle olmak üzere 4 kışlık kolza çeşidi kullanılmış ve çeşitlere $0,25,50,75,100,125,150$ ve $200 \mathrm{mM}$ olmak üzere 8 farklı $\mathrm{NaCl}$ dozu uygulanmıştır. Çimlenme denemesi öncesinde tohumlar \% 5'lik sodyum hipoklorit çözeltisinde 10 dakika süre ile sterilize edilmiştir. Sterilize edilmiş tohumlar, $9 \mathrm{~cm}$ çaplı petri kaplarına, her petride 25 tohum olacak şekilde, kurutma kâğıtları arasına konulmuş ve her petriye belirlenen $\mathrm{NaCl}$ solüsyonundan 10 $\mathrm{ml}$ eklenmiştir. Meydana gelecek buharlaşmayı önlemek için petri kapları ağzı kilitli plastik torbalara konulmuştur. Petri kapları daha sonra iklimlendirme dolabına alınarak, tamamen karanlık ortamda $20 \pm 1{ }^{\circ} \mathrm{C}$ 'de 7 gün boyunca çimlenmeye bırakılmıştır. Deneme süresince tohumlar her gün sayılmış ve $1 \mathrm{~mm}$ kökçük uzunluğuna sahip olanlar çimlenmiş olarak kabul edilmiştir. 7. günün sonunda toplam çimlenen tohumlar sayılarak çimlenme oranı (\%) belirlenmiş ve çimlenme süreleri Matthews \& Khajeh-Hosseini (2007)'ye göre $\sum$ (fx) / $\sum$ f formülü ile hesaplanmıştır. $\mathrm{Bu}$ formülde $\mathrm{f}$ sayım gününde çimlenen tohum sayısını, $\mathrm{x}$ ise sayım yapılan gün sayısını ifade etmektedir. Kökçük ve sürgün boyuna ilişkin ölçümler ise yine 7. günün sonunda 10 fide üzerinden yapılmıştır. Araştırmadan elde edilen veriler Tesadüf Parselleri Deneme Deseni' ne göre, TARIST istatistik paket programı kullanılarak varyans analizine tabi tutulmuş olup, ortalamalar arasındaki farkların önem kontrolü LSD testi ile yapılmıştır.

\section{Bulgular ve Tartışma}

Kışlık kolza çeşitlerinde farklı $\mathrm{NaCl}$ dozlarında çimlenme oranı, çimlenme süresi, kökçük uzunluğu ve sürgün uzunluğu değerlerine ilişkin varyans analiz sonuçları Çizelge 1'de verilmiştir. Çizelge 1'de görüldügü gibi, incelenen tüm özelliklerde artan $\mathrm{NaCl}$ dozlarının etkisi, çeşitler arasındaki farklılık ve çeşit $\mathrm{x}$ tuz interaksiyonu istatistiki olarak \% 1 düzeyinde önemli olmuştur. Çeşit $\mathrm{x}$ tuz interaksiyonun önemli çıkması, artan $\mathrm{NaCl}$ dozlarının incelenen özellikler üzerine etkisinin çeşitlere göre farklılık gösterdiğini ortaya koymaktadır. Ele alınan çeşitlerin farklı $\mathrm{NaCl}$ dozlarındaki çimlenme oranı, çimlenme süresi, kökçük uzunluğu ve sürgün uzunluğu değerleri ve önemlilik grupları Çizelge 2'de verilmiştir.

\section{1. Çimlenme oranı (\%)}

Çizelge 2'de görüleceği üzere, çimlenme oranı bakımından kolza çeşitleri artan $\mathrm{NaCl}$ dozlarından önemli oranda etkilenmiş ve çimlenme oranı tüm çeşitlerde \% 65.33-100.00 arasında değişmiştir. En yüksek çimlenme oranı (\% 100) Triangle çeşidinin $25 \mathrm{mM} \mathrm{NaCl}$ dozunda görülürken, bunu Es Hydromel ve Elvis çeşitlerinin 0 ve $25 \mathrm{mM}$ $\mathrm{NaCl}$ dozundaki değer (\% 98.66) izlemiştir. Buna karşılık en düşük çimlenme oranı ( $\% 65.33$ ve \% 66.66) Elvis ve Es Hydromel çeşitlerinin $200 \mathrm{mM}$ $\mathrm{NaCl}$ dozlarında elde edilmiştir. Araştırmamızda, Es

Çizelge 1- Çeşitlerin farklı NaCl dozlarındaki ortalama değerlerine ilişkin varyans analiz sonuçları

Table 1-The results of variance analysis of the mean values of the cultivars in different $\mathrm{NaCl}$ doses

\begin{tabular}{|c|c|c|c|c|c|}
\hline \multirow{2}{*}{$\begin{array}{l}\text { Varyasyon } \\
\text { kaynaklart }\end{array}$} & \multirow[b]{2}{*}{$S . D$} & \multicolumn{4}{|c|}{ Kareler ortalamast } \\
\hline & & $\begin{array}{c}\text { Çimlenme oranı } \\
(\%)\end{array}$ & $\begin{array}{l}\text { Çimlenme süresi } \\
\text { (gün) }\end{array}$ & $\begin{array}{c}\text { Kökçük uzunluğu } \\
(\mathrm{cm})\end{array}$ & $\begin{array}{c}\text { Sürgün uzunluğu } \\
(\mathrm{cm})\end{array}$ \\
\hline Çeşit & 3 & $221.33^{* *}$ & $17.02^{* *}$ & $28.50^{* *}$ & $7.86^{* *}$ \\
\hline Hata-1 & 8 & 15.17 & 0.01 & 0.71 & 0.21 \\
\hline Tuz & 7 & $956.57^{* *}$ & $11.57^{* *}$ & $151.31^{* *}$ & $81.52^{* *}$ \\
\hline Çeşit xTuz & 21 & $70.60 * *$ & $0.41^{* *}$ & $4.12^{* *}$ & $1.21^{* *}$ \\
\hline Hata & 56 & 24.88 & 0.01 & 1.14 & 0.43 \\
\hline Genel & 95 & 109.03 & 1.49 & 13.69 & 6.79 \\
\hline V.K. & & 5.47 & 1.70 & 17.41 & 15.65 \\
\hline
\end{tabular}

**, $\mathrm{P}<0.01$ düzeyinde önemli 
Çizelge 2- Ele alınan çeşitlerin farklı NaCl dozlarındaki ortalama değerleri ve önem grupları

Table 2- Mean values and significance groups of cultivars in different $\mathrm{NaCl}$ doses

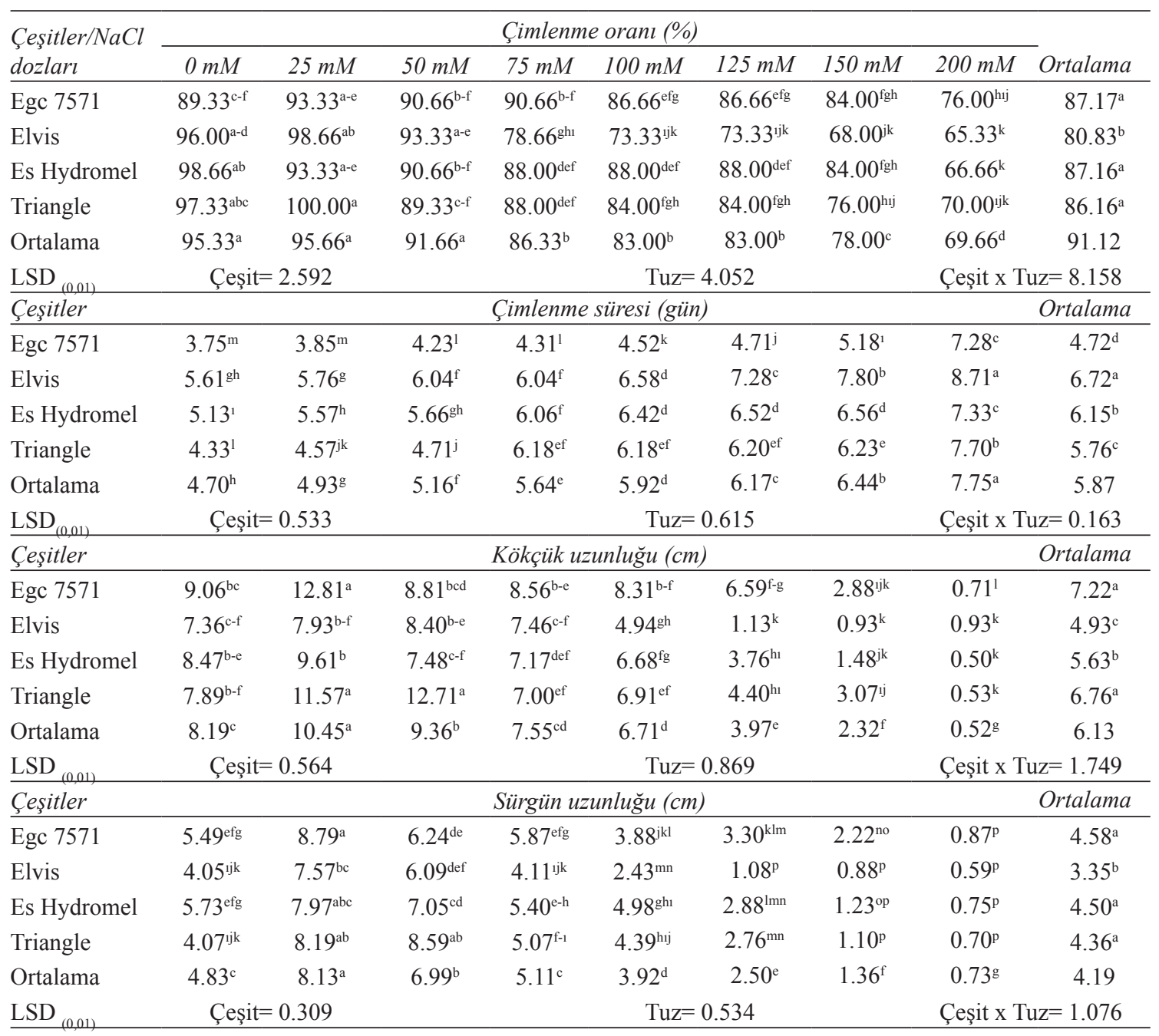

Hydromel dışındaki tüm çeşitlerde, $25 \mathrm{mM} \mathrm{NaCl}$ dozunda çimlenme oranının kontrole göre arttığı görülmüştür. $\mathrm{Bu}$ durum, $\mathrm{Na}^{+}$ve $\mathrm{Cl}^{-}$iyonlarının toksik etki yapmayacak düzeyde olduğunda çimlenmeyi teşvik edici etki göstermesinden ileri gelmiş olabilir. Benzer sonuçlar, düşük tuz seviyelerinde çimlenmenin teşvik edildiğini belirten Ashraf \& Mcneilly (1990), Puppala et al (1999), Shekari et al (2000), Buyuelo-Jiménez et al (2002), Kaya et al (2003), Al-Thabet et al (2004), Kaya et al (2005), Mahmoodzadeh (2008) ve Zamani et al (2010) tarafindan da bildirilmiştir. Ele alınan çeşitler arasında Egc 7571, çimlenme oranı bakımından tuz stresinden en az düzeyde etkilenen çeşit olurken, Elvis tuzluluğa karşı en hassas çeşit olarak öne çıkmıştır. Diğer bir deyişle, artan $\mathrm{NaCl}$ dozlarının çimlenme oranında yol açtı̆̆ azalma, Egc 7571 çeşidinde diğer çeşitlere göre daha az olurken, Elvis çeşidinde en yüksek düzeyde olmuştur. Nitekim kontrol uygulamasına göre $100 \mathrm{mM} \mathrm{NaCl}$ dozunda 
çimlenme oranındaki azalış Egc 7571 çeşidinde $\% 3$ düzeyinde olurken; Es Hydromel çeşidinde $\%$ 11, Triangle çeşidinde \% 14 ve Elvis çeşidinde $\% 24$ oranında olmuştur. Diğer taraftan, 150 ve $200 \mathrm{mM}$ gibi en yüksek $\mathrm{NaCl}$ dozlarında çimlenme oranları Egc 7571 çeşidinde \% 6 ve \% 15 oranında azalırken, Elvis çeşidinde \% 29 ve \% 32 oranında azalmıştır. Artan tuz seviyelerine bağlı olarak çimlenme oranındaki azalma, $\mathrm{Na}^{+}$ve $\mathrm{Cl}^{-}$iyonlarının toksitesinin yanı sıra, artan osmotik basincın çimlenme için gerekli olan suyun tohum tarafindan alınmasını engellemesinden kaynaklanmaktadır (Ekmekçi et al 2005). Ayrıca, Quila (1992) ve Ayaz et al (2000), tuz stresi altındaki bitkilerde görülen bazı metabolik bozuklukların ve çimlenmeyi düzenleyici proteinlerin sentezinin engellenmesinin, çimlenme oranını düşürdüğünü bildirmektedirler.

\section{2. Çimlenme süresi (gün)}

Çeşitlerin çimlenme süresi bakımından $\mathrm{NaCl}$ dozlarından önemli oranda etkilendiği Çizelge 2'de görülmektedir. Farklı NaCl dozlarında çeşitlere ait çimlenme süreleri 3.75-8.71 gün arasında değişmiştir. Egc 7571 çeşidinin kontrol grubunda en hızlı çimlenme (3.75 gün) gerçekleşirken, Elvis çeşidinin $200 \mathrm{mM}$ tuz dozunda en geç çimlenme (8.71 gün) görülmüştür. Egc 7571 ve Elvis dışındaki çeşitlerin çimlenme sürelerinde 25 $\mathrm{mM} \mathrm{NaCl}$ dozundan itibaren önemli bir gecikme dikkati çekmektedir. Buna karşılık, diğer çeşitlerin aksine bu iki çeşide ait çimlenme sürelerinde 100 $\mathrm{mM} \mathrm{NaCl}$ dozundan itibaren önemli gecikmeler olmuştur. $100 \mathrm{mM} \mathrm{NaCl}$ dozundan itibaren her birim tuz artışında Es Hydromel ve Triangle çeşitlerinin çimlenme sürelerinde önemli artış olmazken, Egc 7571 ve Elvis çeşitlerinin çimlenme sürelerinde önemli artışlar görülmüştür. Nitekim tuz dozu 100 mM'dan 125 mM'e yükseldiğinde çimlenme süresi Elvis çeşidinde \% 11 oranında gecikirken, diğer çeşitlerde çimlenme süresindeki gecikme \% 0.3-4 arasında değişmiştir. Çalışmadaki tüm $\mathrm{NaCl}$ ozlarında en hızlı çimlenen çeşit Egc 7571 olurken, Elvis en uzun sürede çimlenen çeşit olmuştur. Diğer bir deyişle, Egc 7571 çeşidi çimlenme süresi bakımından $\mathrm{NaCl}$ dozlarına en toleranslı iken, Elvis en hassas çeşit olarak öne çıkmıştır. Tohumların çimlenme süresi, çimlenme ortamının hava ve su miktarına, sıcaklığına ve tohumların su çekme kapasitesine bağlı olarak değişmektedir. Yaptığımız bu çalışmada, en hızlı çimlenme tüm çeşitlerde kontrol dozunda gerçekleşirken, tüm çeşitler 200 $\mathrm{mM} \mathrm{NaCl}$ dozunda en uzun sürede çimlenmiştir. $\mathrm{Bu}$ durum, artan $\mathrm{NaCl}$ dozları sonucu ortamın osmotik basıncının artmasina paralel olarak tohumların ortamdan su alma yeteneklerinin azalmasının bir sonucu olabilir. Nitekim Maas \& Hoffman (1977) ve Basalah (1991), yüksek tuz seviyesinden dolay1 iyon dengesinin ve osmotik dengenin bozulması sonucu tohumlar tarafından su alımının azaldığını bildirmektedirler. Bulgularımız, artan tuz dozlarına bağlı olarak çimlenme süresinin önemli oranda uzadığını vurgulayan Shekari et al (2000), AlThabet et al (2004), Kaya et al (2005), Jamil et al (2005), Bybordi \& Tabatabaei (2009) ve Day et al (2009) tarafindan tespit edilen bulgular ile uyum içindedir.

\subsection{Kökçük uzunluğu (cm)}

Farklı $\mathrm{NaCl}$ dozlarında kolza çeşitleri kökçük uzunluğu bakımından olumsuz yönde etkilenmiş olup, kökçük uzunluğu değerleri $0.50-12.81 \mathrm{~cm}$ arasında değişmiştir. En uzun kökçük uzunluğu Egc 7571 çeşidinin $25 \mathrm{mM} \mathrm{NaCl}$ dozunda 12.81 $\mathrm{cm}$ olarak ölçülürken, en kısa kökçük uzunluğu $(0.50 \mathrm{~cm})$ Es Hydromel çeşidinde $200 \mathrm{mM} \mathrm{NaCl}$ dozunda ölçülmüştür (Çizelge 2). Çimlenme oranındaki duruma benzer şekilde, toksik etki yapmayacak kadar düşük tuz seviyelerinde $(25 \mathrm{mM})$ tüm çeşitlerde kökçük uzunluğu artış göstermiştir. $\mathrm{Bu}$ durum, daha önce de belirtildiği gibi $\mathrm{Na}^{+}$ve $\mathrm{Cl}^{-}$iyonlarının toksik etki yapmayacak düzeyde olduğunda çimlenmeyi teşvik edici özelliğinden kaynaklanmış olabilir. Nitekim Shekari et al (2000) ve Kaya et al (2005) düşük tuz dozlarının kökçük uzunluğunu teşvik ettiğini bildirmektedirler. $\mathrm{Bu}$ noktadan sonra $(25 \mathrm{mM})$ Triangle çeşidi dişındaki çeşitlerde kökçük uzunluğu önemli oranda azalmış olmakla birlikte, tüm çeşitlerde en keskin düşüşler $100 \mathrm{mM} \mathrm{NaCl}$ dozundan sonra görülmüştür. Nitekim $\mathrm{NaCl}$ dozu 100 mM'dan 125 mM'a 
yükseldiğinde kökçük uzunluğundaki azalma \% 77 ile Elvis çeşidinde en fazla oranda olurken, Egc 7571 çeşidindeki azalma oranı $(\%$ 20) en az düzeyde olmuştur. Triangle ve Es Hydromel çeşitlerindeki azalmalar da sırasıyla \% 36 ve \% 43 oranında gerçekleşmiştir. Kökçük uzunluğundaki azalmalar $125 \mathrm{mM} \mathrm{NaCl}$ dozundan sonra da devam etmiş ve bu azalmalar Egc 751 çeşidinde diğer çeşitlere göre en az oranda görülmüştür. Bu sonuçlar, kökçük gelişmesi yönünden artan tuz stresine Egc 7571 çeşidinin daha toleranslı olduğunu; Elvis'in ise hassas çeşit olduğunu göstermektedir. Bitkilerde kökçük uzunluğu suya ve besin maddelerine ulaşmada etkili olan önemli bir özelliktir. Jamil et al (2005), kökçük uzunluğunun tuzluluktan etkilenen önemli özelliklerden biri olduğunu vurgulamaktadır. $\mathrm{Bu}$ durum, tuzluluğun oluşturduğu $\mathrm{NaCl}$ toksitesi ve köklerin besin maddesi alımındaki düzensizliklerle ilgili olabilir. Nitekim Werner \& Finkelstein (1995) tuzluluğun su alımını ve kök uzunluğunu azalttığını, Khan \& Gulzar (2003) ise tuzluluğun besin alımını azaltarak kök gelişimini olumsuz etkilediğini bildirmektedir. Çalışmamızda elde edilen bulgular, kolzada kök uzunluğunun artan tuz seviyesine bağlı olarak azaldığını bildiren Bahizire (2007), Saied et al (2007), Mahmoodzadeh (2008) ve Day et al (2009) tarafindan da desteklenmektedir.

\subsection{Sürgün uzunluğu (cm)}

Kolza çeşitlerinin farklı $\mathrm{NaCl}$ dozlarındaki sürgün uzunlukları 0.59-8.79 $\mathrm{cm}$ arasında değişmiştir. En uzun sürgün $(8.79 \mathrm{~cm}) \mathrm{Egc} 7571$ çeşidinin $25 \mathrm{mM}$ $\mathrm{NaCl}$ dozunda görülürken, en kısa sürgün uzunluğu $(0.59 \mathrm{~cm})$ Elvis çeşidinin $200 \mathrm{mM} \mathrm{NaCl}$ dozunda ölçülmüştür. Kökçük uzunluğundaki duruma benzer olarak, $25 \mathrm{mM} \mathrm{NaCl}$ dozu tüm çeşitlerde sürgün uzunluğunu kontrole göre önemli oranda arttırmıştır. Ancak, $50 \mathrm{mM} \mathrm{NaCl}$ dozundan itibaren Triangle çeşidi dışındaki tüm çeşitlerde sürgün uzunluğu azalma göstermiştir. Nitekim $\mathrm{NaCl}$ dozu 75 mM'a yükseldiğinde Egc 7571 çeşidi dışındaki tüm çeşitlerin sürgün uzunlukları önemli oranda azalmış ve bu azalma bu \% 41 ile en fazla oranda Triangle çeşidinde görülürken, bunu \% 33 ile Elvis çeşidi takip etmiştir. Diğer taraftan, $75 \mathrm{mM} \mathrm{NaCl}$ dozundan sonra Elvis çeşidinin sürgün uzunluğu \% 50'den fazla azalma göstermiştir. Sürgün uzunluğu açısından Egc 7571 çeşidinde $25 \mathrm{mM}$ $\mathrm{NaCl}$ dozundan itibaren önemli bir düşüş olmasına rağmen, Egc 7571 çeşidi artan $\mathrm{NaCl}$ dozlarına diğer çeşitlere göre daha iyi dayanabilmiştir. Nitekim Egc 7571 çeşidi, tuz stresinin en fazla olduğu $200 \mathrm{mM}$ $\mathrm{NaCl}$ dozunda diğer çeşitlere göre en uzun sürgün uzunluğuna sahip olmuştur. Sürgün uzunluğu, özellikle ekim derinliğini belirlemede önemli bir faktördür. Sürgün uzunluğunun uzun olması ekimin daha derin yapılmasına olanak sağlamakta; ekimin derin yapılması ise, özellikle kuraklık stresinin olduğu yerlerde tohumların çimlenebilmeleri için gerekli olan suyu almalarını kolaylaştırmakta ve iyi bir kök gelişmesi sağlamaktadır. Araştırmamızda, $\mathrm{NaCl}$ dozlarının artmasıyla sürgün uzunluğunun önce uzadığı, sonra önemli oranda azaldığı dikkati çekmektedir. Sürgün uzunluğu $25 \mathrm{mM} \mathrm{NaCl}$ dozunda kontrol grubuna göre \% 68 oranında artmış, ancak bu seviyeden itibaren her birim tuz dozunda önemli oranda azalma görülmüştür. Genel olarak, $75 \mathrm{mM} \mathrm{NaCl}$ dozundan sonra çeşitlerin sürgün uzunluklarında keskin düşüşler başlamış ve tüm çeşitlerde $200 \mathrm{mM} \mathrm{NaCl}$ dozunda en kısa sürgün uzunlukları ölçülmüşsür. $\mathrm{Bu}$ durum, tuz stresine bağlı olarak iyon toksitesi ve osmotik basıncın etkisiyle su alımının engellenmesi ile açıklanabilir. Benzer sonuçlar, gerek kolza gerekse diğer kültür bitkileri üzerinde araştırma yapan Shekari et al (2000), Qasım et al (2004), Şenay et al (2005), Saied et al (2007) ve Zamani (2010)'nin bulgularıyla örtüşmektedir.

\section{Sonuçlar}

Farklı $\mathrm{NaCl}$ dozlarının bazı kışlık kolza çeşitlerinin çimlenmesi üzerine etkisinin araştırıldığı bu çalışmada, artan $\mathrm{NaCl}$ dozları incelenen tüm karakterler üzerine istatistiki olarak önemli olumsuz etki yapmıştır. Ayrıca, çeşit x $\mathrm{NaCl}$ interaksiyonunun önemli çıkması, artan $\mathrm{NaCl}$ dozlarının incelenen özellikler üzerine etkisinin çeşitlere göre farkl1lık gösterdiğini ortaya koymaktadır. Düşük $\mathrm{NaCl}$ dozları kolza çeşitlerinde çimlenme oranı, kökçük ve sürgün uzunluğu üzerine genellikle teşvik 
edici etkide bulunurken, artan $\mathrm{NaCl}$ dozları söz konusu özellikleri tüm çeşitlerde olumsuz yönde etkilemiştir. Nitekim $75 \mathrm{mM}$ ve özellikle 100 $\mathrm{mM} \mathrm{NaCl}$ dozlarından sonra, tüm çeşitlerde $\mathrm{NaCl}$ uygulamalarının incelenen özellikler üzerine olan olumsuz etkisi çok daha belirgin hale gelmiştir. Çalışmada ele alınan özellikler yönünden Egc 7571 çeşidi artan $\mathrm{NaCl}$ dozlarından en az oranda etkilenirken, Elvis en fazla etkilenen çeşit olmuştur.

\section{Kaynaklar}

Al- Thabet S S, Leilah A A \& Al-Hawass I (2004). Effect of $\mathrm{NaCl}$ and incubation temperature on seed germination of three canola (Barassica napus L.). Scientific Journal of King Fasial University 5(1): 8191

Ashraf M \& McNeilly T (2004). Salinity tolerance in Brassica oilseeds. Critical Reviews in Plant Science 23(2): 157-174

Ashraf M \& McNeilly T (1990). Responses of four Brassica species to sodium chloride. Enviromental and Enviromental Botany 30(4): 475-487

Ayaz F A, Kadıoğlu A \& Turgut R (2000). Water stres effects on the content of low molecular weight carbonhydrates and phenolic acids in Ctenanthe setosa (Rosc.) Eichler. Canadian Journal Plant Science 80: 373-378

Bahizire F B (2007). Effect of salinity on germination and seedling growth of canola (Brassica napus L.). Master Thesises. University of Stellenbosch, South Africa

Basalah M O (1991). Effect of salinity on seed germination and growth of sequash (Cucubita pepo L.). The Arab Gulf Journal of Scientific Research 9: 87-97

Bayuelo-Jiménez J S, Craig R \& Iynch J P (2002). Salinity tolerance of phaseolus species during germination and early seedling growth. Crop Science 42: 1584-1594

Bybordi A \& Tabatabaei J (2009). Effect of salinity stres on germination and seedling properties in canola cultivars (Brassica napus L.). Notulae Botanicae Horti Agrobotanici Cluj 37(1): 71-76

Day S, Kaya M D \& Kolsarıcı Ö (2009). Bazı yazlık ve k1şlık kolza (Brassica napus ssp. oleifera) çeşitlerinin çimlenme ve çıkışı üzerine $\mathrm{NaCl}$ konsantrasyonlarının etkisi. Türkiye VIII. Tarla Bitkileri Kongresi, Bildiriler (I): 19-22 Ekim, Hatay, s. 225-228
Doğan M, Kilıç H, Aktan A \& Can N E (2009). Tuz Stresi altındaki Domates (Lycopersicon sp.) Fidelerinde Kalsiyum Miktarı Değişimleri. Fırat Üniversitesi Fen Bilimleri Dergisi 21(2): 103-108

Ekmekçi E, Apan M \& Kara T (2005). Tuzluluğun bitki gelişimine etkisi. OMÜ Ziraat Fakültesi Dergisi 20(3): 118-125

Ergene A (1982). Toprak Bilgisi. Atatürk Üniversitesi Ziraat Fakültesi Yayınları No: 267, Ders Kitapları Serisi No: 42, Erzurum

Jamil M, Lee C C, Rehman S U, Lee D B, Ashraf M \& Rha E S (2005). Salinity ( $\mathrm{NaCl})$ tolerance of Brassica species at germination and early seedling growth. Electronic Journal of Environmental, Agricultural and Food Chemistry 4: 970-976

Kara Ş M \& Keser S (2001). Effect of salinity on plant growth and mineral constituents of maize (Zea mays). Indian Journal of Agricultural Sciences 71(6): 371374

Kaya M D, İpek A \& Öztürk A (2003). Effects of different soil salinity levels on germination and seedling growth of safflower. Turkish Journal of Agriculture and Forestry 27: 221-227

Kaya M D, Kaya G \& Kolsarıcı Ö (2005). Bazı Brassica türlerinin çimlenme ve çıkışı üzerine $\mathrm{NaCl}$ konsantrasyonlarının etkisi. Tarım Bilimleri DergisiJournal of Agricultural Sciences 11(4): 448-452

Khan M A, Ungar I A \& Showalter A M (2000). Effect of sodium chloride treatments on growth and ion accumulation of the halophyte Haloxylon recurvum. Communications in Soil Science and Plant Analysis 31(17-18): 2763-2774

Khan M A \& Gulzar S (2003). Germination responses of Sporobolus ioclados: A saline desert grass. Journal of Arid Environments 53(3): 387-394

Kuşvuran Ş, Ellialtıoğlu Ş, Abak K \& Yaşar F (2007). Bazı kavun (Cucumis sp.) genotiplerinin tuz stresine tepkileri. Tarım Bilimleri Dergisi- Journal of Agricultural Sciences 13(4): 39-404

Mahmoodzadeh H (2008). Comparative study of tolerant and sensitive cultivars of Brassica napus in response to salt conditions. Asian Journal of Plant Sciences 7(6): 594-598

Mass E V \& Hoffman G J (1977). Crop salt tolerance: Current assessment. Journal of the Irrigation and Drainage Division 03(2): 115-134 
Matthews S \& Khajeh-Hosseini M (2007). Length of the lag period of germination and metabolic repair explain vigor differences in seed lots of maize (Zea mays). Seed Science Technology 35: 200-212

Mohammadi G R (2009). The influence of $\mathrm{NaCl}$ priming on seed germination and seedling growth of canola (Brassica napus L.) under salinity conditions. American-Eurasian Journal Agriculture \& Environment Science 5(5): 696-700

Öncel I \& Keleş Y (2002). Tuz stresi altındaki buğday genotiplerinde büyüme, pigment içeriği ve çözünür madde kompozisyonunda değişmeler. Cumhuriye Üniversitesi, Fen Bilimleri Dergisi 23(2): 8-16

Puppala N, Fowler J L, Poindexter L \& Bhardwaj H L (1999). Evaluation of salinity tolerance of canola germination. In: Perspectives on New Crops and New Uses; ASHS Press: alexandria, VA, pp. 251-253

Qasım M, Ashraf M, Ashraf Y, Ahmad R \& Nazlı S (2004). Some growth related characteristics in canola (Brassica napus L.) under salinity stress. İnternational Journal of Agriculture \& Biology 6(4): 665-668

Quila A D (1992). Water uptake and protein synthesis in germinating wheat embryos under the osmotic stress of polyethylene glycol. Annals of Botany 69: 167-171

Saied M S, Farahbakhsh H \& Mude A A M (2007). Effect of salt stress on germination, vegetative growth and some physiological characteristics of canola. Journal of Science \&Technology Agriculture\& Natural Research 11(4): 191-203
Shekari F, Khoii F R, Javanshir A, Alyari H \& Shkiba M R (2000). Effect of sodium chloride salinity on germination of rapeseed cultivars. Turkish Journal of Field Crops 5(1): 21-28

Şekeroğlu N, Kara Ş M, Dede Ö \& Aşkın T (1999). Effect of salinity on germination, early seedling growth, $\mathrm{Na}$ and $\mathrm{K}$ constituents in chicpea. Turk Journal of Field Crops 4: 79-84

Şenay A, Kaya M D, Atak M \& Çiftçi, C Y (2005). Farklı tuz konsantrasyonlarının bazı ekmeklik buğday çeşitlerinin çimlenme ve fide gelişimi üzerine etkileri. Tarla Bitkileri Merkez Araştırma Enstitüsü Dergisi 14(1): 50-55

Türkan G (2008). Bitki fizyolojisi. Palme Yayınları No. 455, s.690, Ankara

Werner J E \& Finkelstein R R (1995). Abidopsis mutants with reduced response to $\mathrm{NaCl}$ and osmotic stress. Physiologia Plantarum 93: 659-666

Zadeh H M \& Naeni M B (2007). Effect of salinity stress on the morphology and yield of two cultivars of canola (Brassica napus L.). Journal of Agronomy 6: 409-414

Zamani S, Nezami M T, Habibi D \& Khorshidi M B (2010). Effect of quantitive and qualitative performence of four canola cultivars (Brassica napus L.) to salinity conditions. Advances in Enviromental Biology 4(3): $422-427$ 